\title{
Policing during a global health pandemic: Exploring the stress and well-being of police and their families
}

\author{
Jacqueline M. Drew and Sherri Martin ${ }^{\dagger}$
}

This article is related directly to the $6^{\text {th }}$ International Law Enforcement $\mathcal{E}$ Public Health (LEPH) Virtual Conference in March 2021.

\begin{abstract}
Law enforcement personnel attend critical incidents that are typically short-lived and geographically confined. However, the recent global health pandemic potentially impacts on every officer, every shift, throughout the world. This research is one of the first survey studies of stress and mental health impacts of COVID-19 on United States police and their families. The study found that the pandemic has created additional stress for police and their families, elevating stress levels in an already highly stressed population. For police officers, sources of stress were predominately associated with the fear of infecting their families and the enforcement of restrictions. The stress created by the pandemic exceeds that of other commonly experienced critical incidents in policing. The current findings indicate that police and their families expect to experience longer-term, harmful mental health impacts. This research provides important insights for police agencies, as well as those who work to support and improve the well-being of police. The pandemic is impacting now on the current stress levels of police and is likely to create a legacy that must be managed into the future.
\end{abstract}

Key Words COVID-19; police mental health; police well-being; police stress.

\section{INTRODUCTION}

No country or community has escaped some impact from the COVID-19 pandemic that swept across the world beginning in the early months of 2020. Those in law enforcement are often called upon to respond to either man-made critical incidents (such as terrorist events) or natural disasters (such as hurricanes); however, these events are typically short-lived and confined to specific geographic locations (Jennings \& Perez, 2020). As officers enacted mandates designed to slow the progress of the pandemic by reducing the chance of spreading infection, they themselves did not have the opportunity to isolate (Papazoglou et al., 2020; Stogner et al., 2020). The global health pandemic is a critical event that has the potential to impact every officer, on every shift throughout the world - this event is unprecedented in recent history, in terms of both its scale and impact (Drew \& Martin, 2020). Drawing on survey data of United States police, this paper explores the immediate impacts of COVID-19 on the health and well-being of officers who served during this time.
The current research provides an early snapshot (from June to August 2020) of the experiences of police personnel who served in law enforcement roles in the United States following the declaration of a global health pandemic. This research makes an important contribution to the existing body of empirical academic literature, previous research on the impact of these types of events being limited (Laufs \& Waseem, 2020). It is noted that Frenkel et al. (2021) have recently published research with a sample of European police examining stress, demands, and coping resources during COVID-19. Our research provides one of the first empirical insights into the mental health effects of COVID-19 on United States police. We need to urgently consider how best to address the unique and/or compounding impacts of COVID-19 on police and their families.

\section{LITERATURE REVIEW}

The following discussion begins with a brief overview of the data that was available up to October 2020, about the infection 
and death rates of law enforcement officers since the beginning of the pandemic. Based on an understanding of physical impacts, we then consider the likely mental health and well-being outcomes for police and their families.

\section{COVID-19 Infections and Law Enforcement}

The National Police Foundation (NPF) developed a COVID19 Law Enforcement Impact Dashboard (NPF, 2020). From March to October 2020, they reported that 6,535 officers had been exposed to COVID-19 (some contact with those who potentially had the virus), 2,304 had been unable to work, and 754 officers had been diagnosed themselves as being infected (NPF, 2020). Recent data provided by the National Fraternal Order of Police (FOP) (2020) indicates that 247 law enforcement personnel have died of COVID-19-related illnesses.

To provide a point of reference, we can compare the COVID-19 data reported above with other common indicators of the dangers and psychological outcomes associated with police work. In 2019, the Officer Down Memorial Page (2020) reported 147 line-of-duty deaths in the United States. Blue H.E.L.P. reports that, up to October 2020, there were 144 law enforcement suicide deaths (Blue H.E.L.P., 2020). From this comparison, COVID-19 does represent a significant event that has impacted, and will likely continue to impact, the health of law enforcement personnel.

\section{Impact of COVID-19 on Law Enforcement}

Based on analyses of previous crises (Stogner et al., 2020), three key interrelated areas are relevant to the current pandemic context. These include changes to law enforcement practices, changes in personal perceptions of officer safety, and increased stress and negative impacts on psychological well-being.

\section{Changes to Law Enforcement Practices}

In the United States, public health acts were enacted across states, expanding the duties of law enforcement officers to encompass enforcement of physical distancing, travel restrictions, and mandatory quarantining (Jennings \& Perez, 2020; Rothstein, 2015). This created service demands on police in addition to their normal duties. If not enacted effectively, these mandates have the potential to negatively impact on police-community relations and public trust and confidence in police (Laufs \& Waseem, 2020; Stogner et al., 2020).

Stogner et al. (2020) note the dual responsibility of law enforcement that requires officers to control often violent behaviour but also ensure compliance with public health measures. Despite the restrictions in place, there were large public demonstrations fuelled by racial tensions resulting from the deaths of Breonna Taylor and George Floyd (Stogner et al., 2020). These were in addition to several mass demonstrations in direct response to government mandates to wear masks and "shelter in place" or "stay-at-home orders" (Prasad, 2020). The refusal of protesters to wear masks and the heightened likelihood of physical altercations between these protesters and police further increased the dangers for police (Laufs \& Waseem, 2020).

Similar to directives given to the wider community, it is essential that law enforcement personnel who are sick do not report to work and risk spreading infection (Jennings \& Perez, 2020). It was reported that, for the NYPD in April $2020,5,600$ officers, which represents $15 \%$ of its workforce, had reported in sick and were off duty (ABC, 2020). Understaffed agencies impact the police response available but also increase the physical and psychological stress of officers who are left to cover extra shifts and workload (Laufs \& Waseem, 2020).

\section{Officer Safety}

The risk of COVID-19 infection is recognized as a concern for all first responders. Guidelines issued by the Centers for Disease Control and Prevention (CDC, 2020) include physical distancing (6-foot or 2-metre distance between self and others), increased hygiene practices, and the use of personal protective equipment (PPE). As a result of their duties, police come into close personal contact with community members and, inevitably, will be at increased risk of infection (Jennings \& Perez, 2020). Alarmingly, the Federal Bureau of Investigation (FBI) warned agencies that some extremist groups were encouraging individuals to intentionally infect officers (Jennings \& Perez, 2020; Margolin, 2020).

Provision of PPE: Much discussion in the early stages of the pandemic focused on the speed with which agencies were able to distribute personal protective equipment (PPE) (Stogner et al., 2020). It was reported that during the first month, the most desired-and most depleted-PPE items were respirators, gowns, and eye protection (Jennings \& Perez, 2020; NPF, 2020). The provision of sufficient and effective PPE is likely to be critical in influencing the perceptions and feelings of officers regarding their personal safety and perceived likelihood of infection.

Fear of infection: The possibility of infection from COVID-19 was, and remains, an omnipresent threat for law enforcement. There is a need to be hypervigilant about safety protocols, and those who have tested positive must return to the very workplace in which they contracted the virus once they have recovered (Dazio et al., 2020). Officers may fear infection themselves as they move about the community and may be fearful of infecting their family members when returning home (Stogner et al., 2020). COVID-19 has the potential not only to increase on-the-job stress but to impact on officer and family stress outside of work.

\section{Stress and Psychological Impact}

Officers are already at greater risk of experiencing negative psychological consequences (Drew \& Martin, 2020). Those in the law enforcement profession, compared with the general population, are more likely to have poor mental health and well-being, with elevated levels of post-traumatic stress, anxiety, and depression (Carleton., et al., 2020; Klimley et al., 2018; Regehr et al., 2019). We often focus on the stress of critical incidents in policing when studying mental health outcomes, with police exposed on average across their careers to between 168 and 188 traumatic events (Chopko et al., 2015; Weiss et al., 2010). We know that large-scale critical incidents (e.g., 9/11 and Hurricane Katrina) are associated with poor mental health outcomes (Carlier et al., 1997; Lowell et al., 2018; Pole et al., 2001), and well-being can continue to deteriorate over time (Bowler et al., 2012). Drew and Martin (2020) conclude that COVID-19 meets the definition of a critical incident and, as such, represents a significant threat to police mental health. Further, it has been found that past and existing stressors make it more difficult to cope with 
new stressors (Slocum, 2010). The impact of the addition of COVID-19 to the other, well-documented operational and organizational stressors already being experienced by police must be better understood.

\section{Current Study}

The current study contributes to the small, existing body of literature that has studied the mental health and wellbeing impacts of public health emergencies and, more specifically, pandemics. The findings presented here give some initial insights into the mental health effects of the global health pandemic on United States police officers and their families.

\section{METHODS}

\section{Sample}

A survey was made available via an online survey platform (Survey Monkey) to all members of the National Fraternal Order of Police (FOP) beginning June 2020 (the survey remains open as COVID-19 continues to be an active event). The current study is based on data that was collected from June to August 2020. The FOP is the largest organization of sworn law enforcement officers in the world, with more than 355,000 members. FOP members were notified of the survey via inter-organization e-mail, newsletters, educational webinars, and word of mouth at in-person meetings.

When the following analysis was undertaken, a sample of 209 active officers (currently serving in law enforcement during the pandemic) was obtained. The sample included 173 male $(82.8 \%)$ and 34 female $(16.3 \%)$ officers. The largest group of officers was between 46 and 55 years of age (45\%). Most officers had more than 16 years of service (16 to 20 years: $19.6 \%$; 21 to 25 years: $21.1 \%$, and over 25 years: $31.4 \%$ ) and the largest percentage of officers held the rank of corporal/ sergeant $(32.5 \%)$.

\section{Survey Instrument}

\section{Demographics}

A short online survey instrument was constructed by the National Director of Wellness Services (FOP). The survey included a range of demographic questions, such as whether respondents were active or retired, age, gender, current rank, years of service and geographic location. Respondents were asked a series of questions about personal and agency infection and death rates resulting from COVID-19.

\section{Police Agency Support}

Data was collected regarding the level of support the agency had provided to deal with additional physical and mental/ emotional stresses during the pandemic and the provision of PPE (three questions). Responses were collected using a 5-point Likert scale, from "strongly disagree" to "strongly agree" and the option, "I felt no additional physical and mental/ emotional stresses."

\section{Exposure}

The survey collected information about the officers' level of potential exposure in their current role. They were asked, "How would you rate your level of potential exposure in your role as a law enforcement officer interacting with the general community during the COVID-19 pandemic? (i.e., patrol officers may have very high exposure, officers on desk duty may have some exposure, etc.)." Responses were collected using a 5-point Likert scale, from "no exposure" to "very high exposure."

\section{Pre-Pandemic and Pandemic Stress-Officers and Families}

Pre-pandemic stress: Two questions were asked about stress prior to the pandemic. Officers were asked, "How would you rate your level of work-related stress prior to the pandemic?" and "How would you rate your family's level of stress related to your law enforcement occupation prior to the pandemic?" Responses were collected using a 6-point Likert scale, from "experienced no stress" to "very high stress."

Pandemic stress: Officers were then asked how their own and their family's stress levels (two questions each) have been impacted during the COVID-19 pandemic. Responses to all four questions were collected using a 5-point Likert scale, ranging from "much higher" to "much lower."

Sources of pandemic stress: To understand the sources of stress experienced during COVID-19, officers were asked to rate how much stress resulted from a list of five sources: enforcement of restrictions, frustration with shortage of equipment/services (specifically PPE), increased number of calls for police service, fear of infection/death of self, and fear of infection of partner/family. All sources of stress were rated on a 6-point Likert scale, from "no stress at all" to "very high stress."

Comparison of pandemic stress with previous critical incidents: Officers were asked to identify, from a provided list, the types of critical incidents to which they had been previously exposed. The list included critical incidents such as officerinvolved shooting, violent encounter that endangered my life, and suicide of a co-worker. Officers were asked, using a 5-point rating scale from "strongly disagree" to "strongly agree," to rate whether they had experienced greater stress working during the pandemic compared with the previous critical incident.

\section{Longer-Term Impacts of the Pandemic}

To understand the expected longer-term impacts of the pandemic, officers were asked, "I believe that COVID-19 will impact on my mental well-being in the long term" and "I believe that COVID-19 will impact on my family's stress about the dangers of my work in the long term." A 5-point scale, from "strongly disagree" to "strongly agree," was provided.

\section{RESULTS}

\section{Exposure and Infection Rates}

At the time of survey completion, 5.3\% of the sample indicated that they had been diagnosed with COVID-19. Of the sample, over half indicated that officers in their agency had been diagnosed, with the largest group of respondents (35.9\%) reporting between 1 to 10 officers. Sixteen officers $(7.7 \%)$ reported that at least one officer within their agency had died. Only one officer indicated that they had no exposure to COVID-19. Of the sample, $40.7 \%$ indicated some/moderate or very low exposure and $58.8 \%$ indicated high or very high exposure. 
Agency Support-PPE, Physical Dangers, and Mental/ Emotional Stresses

Over half of the sample believed that PPE provision by their agency was appropriate (Table I). Of the sample, 38.8\% of officers either disagreed that the agency had provided support for physical dangers or gave a neutral response. For mental/ emotional stresses, $64.7 \%$ of officers either disagreed that support was provided or gave a neutral response. More officers were positive about the support of their agency regarding physical dangers $(60.1 \%)$ and PPE provision $(54.6 \%$, data not shown) than support for mental/emotional stresses (35.4\%).

\section{Pre-Pandemic and Pandemic-Related Stress}

\section{Pre-Pandemic Stress-Officers and Family}

Examining pre-pandemic stress, only one officer indicated no stress at all related to their work, and four officers indicated that their family experienced no stress. For officers, the mean stress level was 3.21 out of 5, with $33.1 \%$ of the sample reporting high or very high stress. Perceptions of family stress reported by officers produced a mean stress level of 3.20 out of 5 , with $31.2 \%$ of the sample indicating high or very high stress.

\section{Pandemic-Related Stress-Officers}

For $78.8 \%$ of the sample, officer stress levels were slightly higher $(44.7 \%)$ or much higher $(34.1 \%)$ compared with prepandemic levels.

Exposure: A Mann-Whitney U test was performed to examine exposure to COVID-19 and the elevation of stress during COVID-19. The test indicated a non-significant difference between officers who reported low and high exposure on elevated COVID-19 stress, $U=1,358.0, p>0.05$.
TABLE I Agency support for physical dangers and mental/emotional stresses

\begin{tabular}{lccc}
\hline & $\begin{array}{c}\text { Strongly/ } \\
\text { Somewhat } \\
\text { Disagree }\end{array}$ & $\begin{array}{c}\text { Neither } \\
\text { Agree/ } \\
\text { Disagree }\end{array}$ & $\begin{array}{c}\text { Somewhat/ } \\
\text { Strongly } \\
\text { Agree }\end{array}$ \\
\hline Physical dangers & 24.2 & 14.6 & 61.1 \\
Mental/emotional stresses & 33.8 & 30.8 & 35.4
\end{tabular}

PandemicStress Compared with Pre-COVID-19:Officers weredividedintotwogroupsbased on theirreported pre-COVID-19 stress levels, low and some/high stress. A Mann-Whitney U test indicated a significant difference between officers who reported low and high pre-COVID stress on COVID-19 stress outcomes, $\mathrm{U}=3,630.0, p<0.01, r=0.05$. Those who reported some/high pre-COVID stress reported a greater elevation of stress (Figure 1). Of those officers who reported low stress levels prior to the pandemic, $62.5 \%$ reported that their stress levels were greater due to COVID-19. A comparatively larger percentage of officers reported elevated levels of stress due to COVID-19 if they had been experiencing some or high stress pre-pandemic (90.8\%).

\section{Pandemic-Related Stress-Families}

With respect to family stress levels, $74.6 \%$ of the sample reported family stress levels were slightly higher $(42.1 \%)$ or much higher (32.5\%) during COVID-19 than prior to the pandemic.

Exposure: A Mann-Whitney U test was performed, and a significant difference was found between officers who reported low and high exposure on family stress, $\mathrm{U}=1,159.5$, $p<0.05, r=0.02$. Officers who were more highly exposed reported greater family stress.

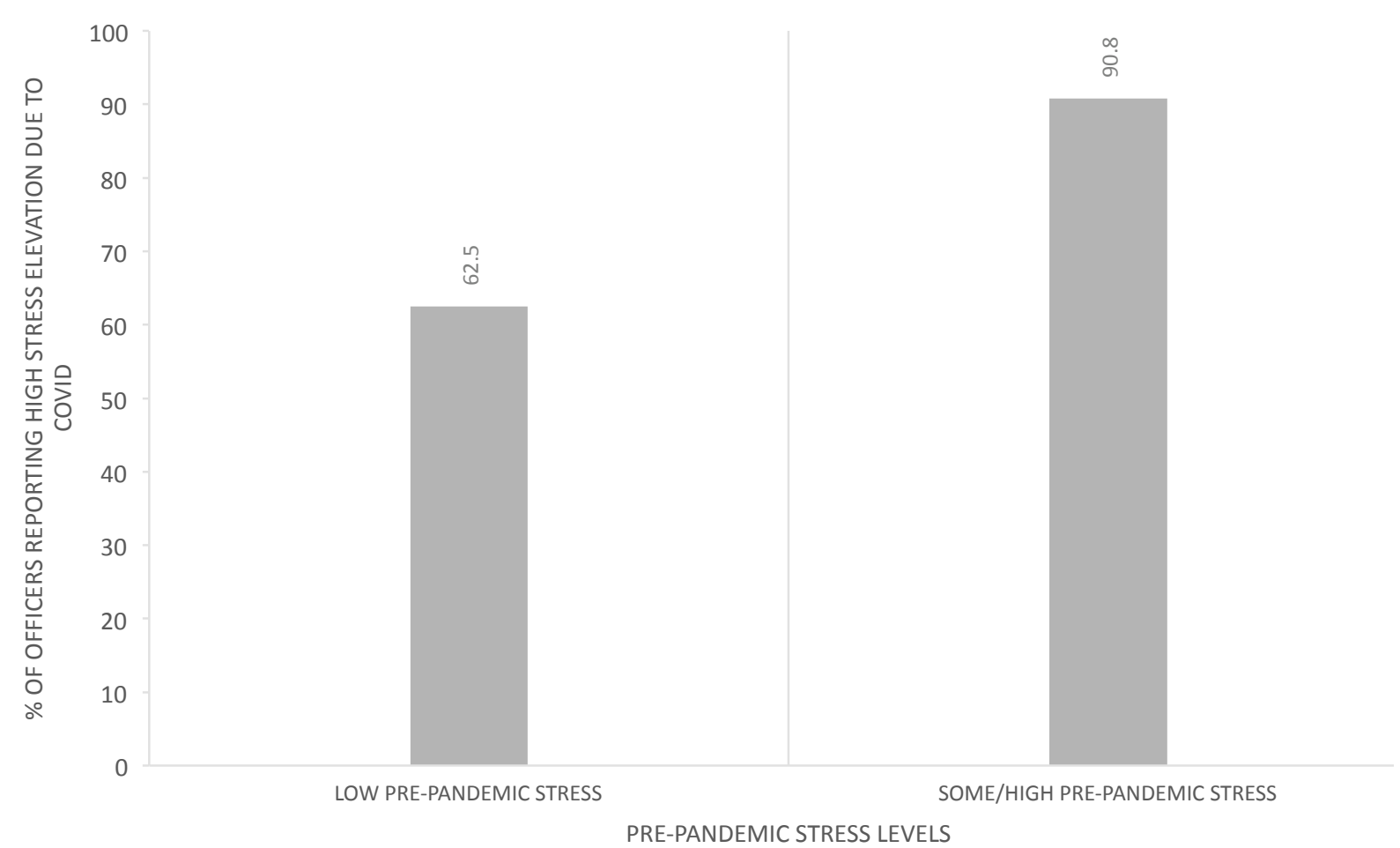

FIGURE 1 Pre-COVID-19 stress levels and stress elevation during COVID-19 


\section{Sources of Pandemic-Related Stress}

Five specific sources of pandemic-related stress were measured in the survey (Table II). The most highly endorsed stress-inducing factor related to fears of infecting family. From a work perspective, the largest group of officers indicated that stress was experienced resulting from enforcing restrictions.

\section{Comparison of Pandemic-Related Stress and Previous Critical Incidents}

We analyzed the response of those officers who had experienced at least one previous critical incident. We found that $57.4 \%$ of officers agreed or strongly agreed that they experienced more stress during COVID-19 compared with the level of stress they experienced as a result of previous critical incidents. The mean stress score was 3.52 on a 5 -point scale.

\section{Longer Term Impacts of Pandemic}

Of the officers surveyed, $39.0 \%$ reported that they would have long-term mental health effects from COVID-19. Survey responses indicated that $51.2 \%$ of officers reported that COVID-19 would elevate family stress about the dangers of police work.

Impact on officers: A Mann-Whitney U test indicated a significant difference between officers reporting low and high levels of stress due to COVID-19 and longer-term mental health outcomes, $\mathrm{U}=1619.0, p<0.01, r=0.05$. Those who reported greater elevation of stress resulting from COVID-19 reported greater expected likelihood of longer-term mental health issues. As shown in Figure 2, over half of all officers in the low stress elevation group $(61.36 \%)$ did not believe that COVID-19 would have a long-term impact on mental health. Conversely, almost half of all officers in the high stress elevation group (47.24\%) reported that stress resulting from COVID-19 would have a long-term impact.
Table II Sources of pandemic-related stress

\begin{tabular}{lcccc}
\hline \multicolumn{1}{c}{ Sources of Stress } & $\begin{array}{c}\text { No } \\
\text { Stress }\end{array}$ & $\begin{array}{c}\text { Very Low/ } \\
\text { Low }\end{array}$ & Some & $\begin{array}{c}\text { High/ } \\
\text { Very High }\end{array}$ \\
\hline Fear of infection (self) & 16.8 & 25.5 & 27.9 & 29.8 \\
Fear of infection (family) & 10.0 & 18.2 & 19.6 & 52.2 \\
Increased calls for service & 11.5 & 30.1 & 37.7 & 21.1 \\
Enforcement of restrictions & 10.0 & 21.1 & 26.3 & 42.6 \\
Lack of PPE & 13.9 & 28.7 & 23.0 & 34.4 \\
\hline
\end{tabular}

PPE $=$ personal protective equipment

Impact on families: A Mann-Whitney U test indicated a significant difference between officers who reported low and high exposure and long-term impact on families perception of the dangers of police work, $\mathrm{U}=1,017.5, p<0.01, r=0.03$. A greater percentage of those with high exposure to COVID19 expected that their families would experience long-term impacts, increasing the concerns of families about the dangers of police work. As shown in Figure 3, almost $54 \%$ of officers who had high exposure to COVID-19 compared with around $24 \%$ of officers who had low exposure to COVID-19 reported that family concern about the dangers of police work would persist over time.

A significant difference was also found between officers who reported differing levels of stress experienced by families and long-term expectations regarding the danger of police work, $\mathrm{U}=1,367.5, p<0.001, r=0.27$. Those whose families experienced higher stress during COVID-19 expected greater long-term impacts on their family's perception of the dangers of their policing duties. As shown in Figure 4, 64.74\% of officers indicated that their families experienced high stress elevation resulting from COVID-19 reported that this experience would continue to impact on their family's perception about the dangers of police work over time.

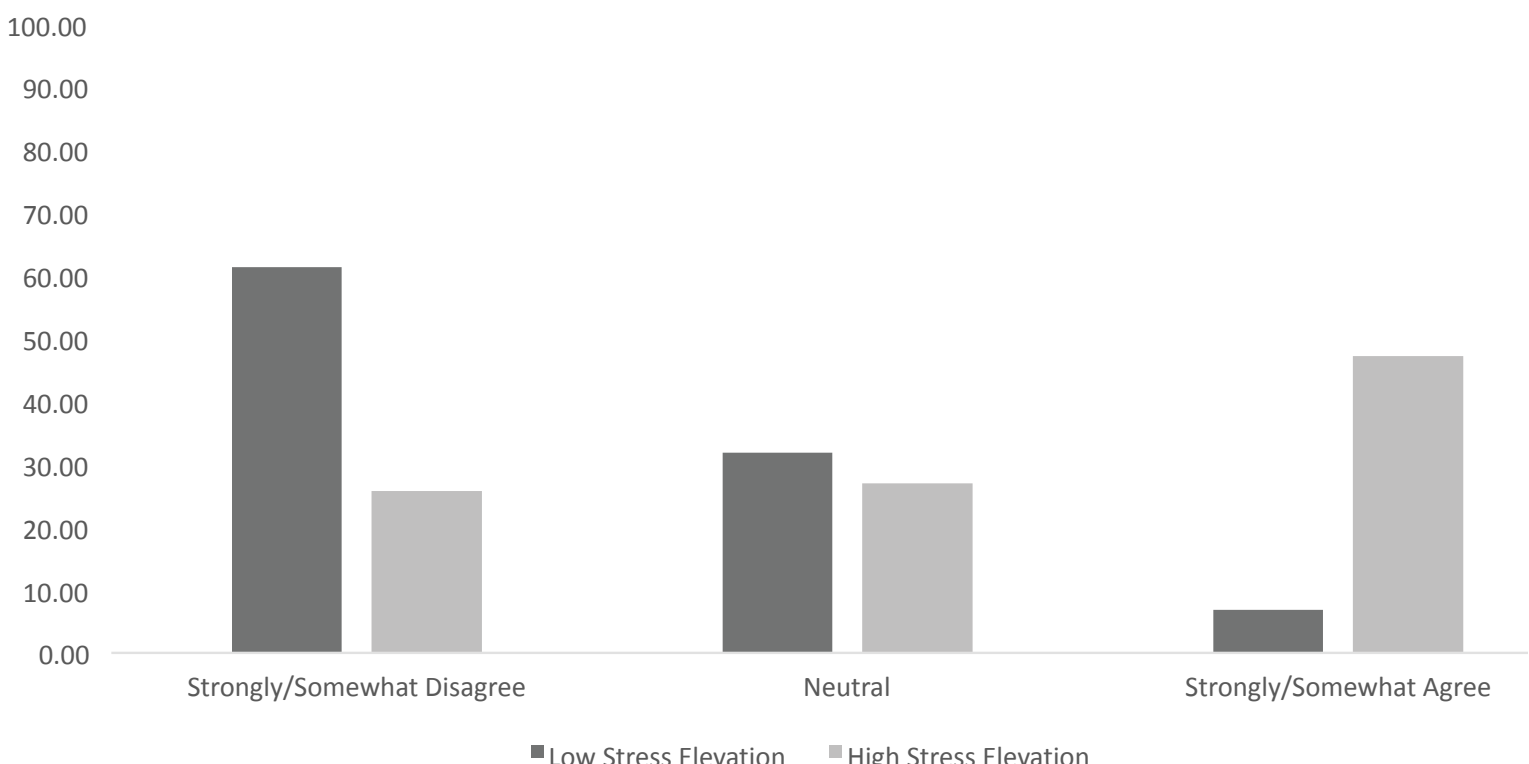

FIGURE 2 Officer stress resulting from COVID-19 and long-term mental health impacts 


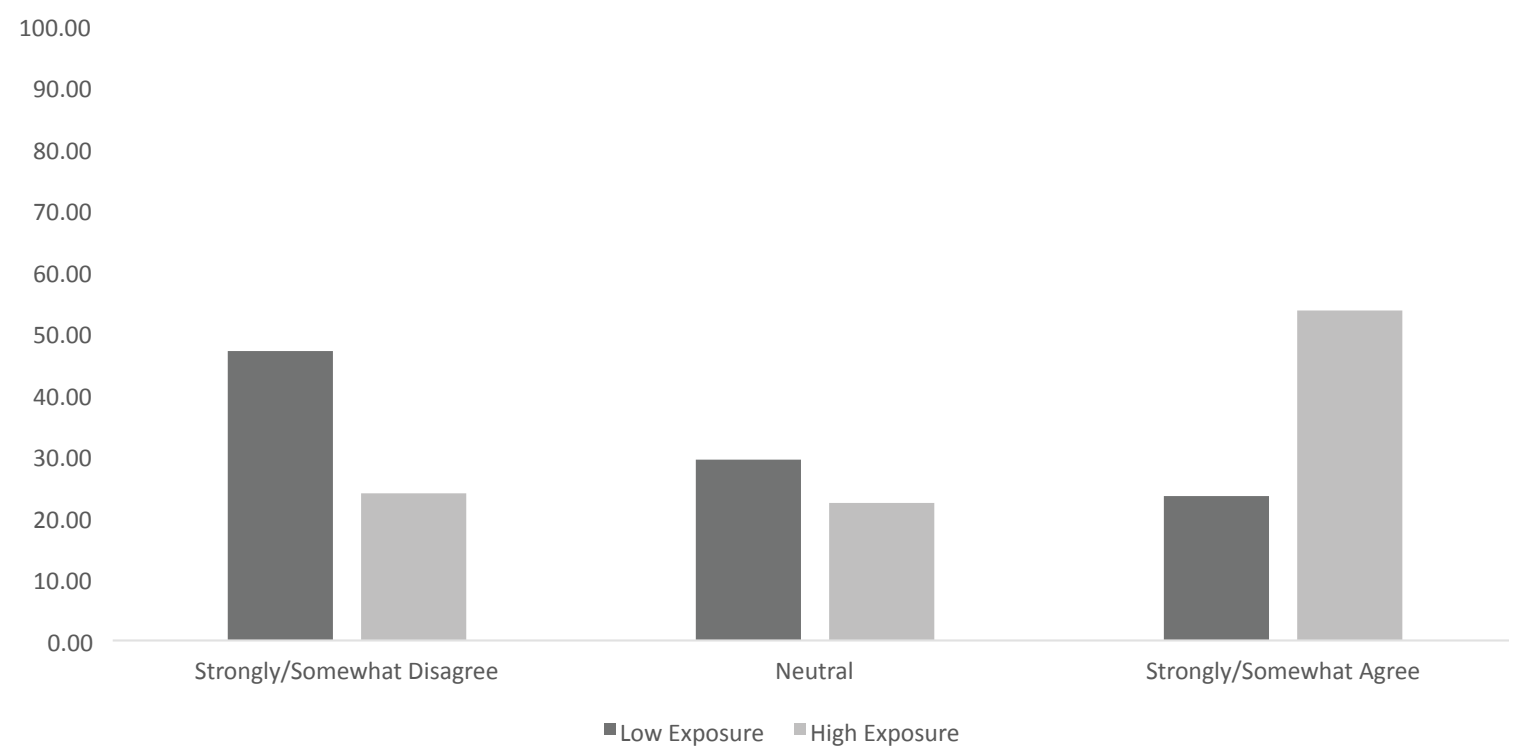

FIGURE 3 Officer exposure to COVID-19 and long-term concerns of family about dangers of police work

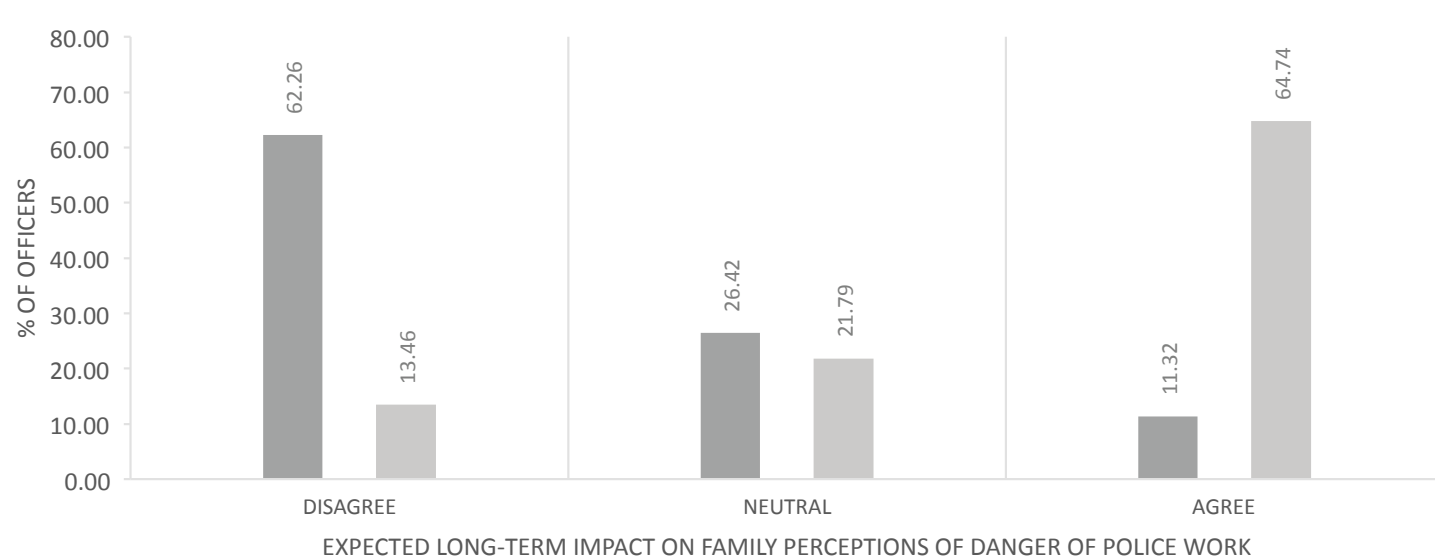

- Low Stress Experienced by Family Due to COVID-19 High Stress Experienced by Family Due to COVID-19

FIGURE 4 Concerns of officers' families about dangers of police work in the long term and levels of COVID-19-related stress experienced by families

\section{DISCUSSION}

The purpose of the current research was to provide a snapshot of key experiences, specifically related to police stress, mental health, and well-being of United States police during COVID-19. Much focus, and rightly so, will be on the numbers of officers who lost their lives to the virus, simply by doing their job. However, we need to also consider urgently what unique and/or compounding impacts COVID-19 has had on the psychological well-being of police-a population, prior to the pandemic, who already routinely reported elevated levels of stress and a comparatively high prevalence of mental health issues compared with other occupations (Carleton et al., 2020).

As stated by Stogner et al. (2020, p. 10) "while COVIDrelated precautions are being labelled 'the new normal,' it is imperative that steps be taken to ensure that pandemic- worsened job stress levels not become 'the new normal' for law enforcement officers." The findings of the current research support the large body of previous research (Carleton et al., 2020; Klimley et al., 2018; Regehr et al., 2019) that officers were, prior to the pandemic, already experiencing relatively high levels of work-related stress. The pandemic created additional stress, with almost $80 \%$ of the sample indicating that their stress levels were slightly higher or much higher.

\section{COVID-19 as a Critical Incident}

In understanding the proportionality and comparability of stress during COVID-19 with stress during other incidents, almost $60 \%$ officers who had previously experienced a critical incident felt that this was a more stressful time for them than those experiences. This has significant implications for the required response of police agencies in supporting the 
mental health and well-being of their personnel. Research is clear that the dangers of police work and critical incidents is a major contributor to the high prevalence of Post-Traumatic Stress Disorder (PTSD) and associated mental health outcomes, and the impacts can be long term (Bowler et al., 2012; Carlier et al., 1997; Laufs \& Waseem, 2020; Lowell et al., 2018; Pole et al., 2001; West et al., 2008).

Based on previous research from large-scale emergencies (Liu et al., 2014; West et al., 2008), we would expect that those in higher exposure groups would simply experience greater pandemic-related stress. This was not found in the current research. The trajectory and impact of COVID-19 as a critical incident may be unique. We may not be able to simply directly translate our understanding from other crises and emergencies. Further research should be undertaken to validate these findings.

\section{Understanding Sources of COVID-19 Stress}

This study found a larger proportion of officers rated enforcement of restrictions (42.6\%) and lack of PPE (34.4\%) more stressful (high/very high stress) than fear of being infected personally (29.7\%). These issues are under the control of police agencies and leaders. Agencies and leaders can positively influence well-being by more effectively addressing these operational issues and must step up to that challenge.

The current findings support the conclusions of Drew and Martin (2020), who stated that COVID-19 creates an atypical level of perceived risk for families. The usual stress and worry experienced by families of law enforcement officers is almost always regarding the danger to their law enforcement loved one, rather than danger to themselves. The COVID environment has changed this and the current context has meant that family well-being is being more directly impacted by the job of policing than previously.

\section{Cumulative Stress-The Addition of COVID-19 Experiences}

Previous research has found that stress, particularly critical incident stress, is cumulative (Maguen et al., 2009; Marshall, 2016; Slocum, 2010) and this seems to be the experience of officers in the current study. Officers who were highly stressed pre-pandemic found the stress of COVID-19 even more impactful or, perhaps, overwhelming. Given previous research that has found that past and existing stressors make it more difficult to cope with new stressors (Slocum, 2010), this is a group within law enforcement that we should seek to identify and target for support.

\section{COVID-19 and Police Families}

This research has highlighted the need to think more broadly about familial network impacts. Almost two-thirds of the sample rated the elevation of stress, compared with the usual stress experienced by families due to theirjob, as slightly higher or very much higher. We found that those who perceived higher elevation of family stress experienced as a result of COVID-19 were also significantly more likely to feel that their family would, in the longer term, experience greater stress about the dangers of police work.

The implications of these findings are two-fold. First, there is a need to consider what additional supports are required for police families to assist them in managing the impact of stress. Previous studies (e.g., Karaffa et al., 2015) have found that law enforcement families struggle with the impact of policing on their home life. Second, we need to give officers the skills to navigate the impact of their job on their family. This should already be a priority for agencies, given the growing body of evidence that police work has major impacts on the non-work domain (McQuerrey Tuttle et al., 2018).

\section{Limitations and Future Research}

The current research has several limitations. It is acknowledged that the data collected relied on officers being able to separate out the impacts that they experienced because of COVID-19 from other sources, particularly the potential impact of mass demonstrations. To help officers to focus on the specific impacts of COVID-19, each relevant survey question was constructed to remind officers to answer the question with respect to COVID-19 only. A further limitation was that the survey was designed as a short survey to collect initial data about the impact of the pandemic. To be time efficient, most variables were measured using a single item question rather than a multi-question scale. It is acknowledged that the veracity of conclusions is limited by the small sample size. The survey was first distributed in June 2020, just as the racefuelled protests following the death of George Floyd began to increase. The response rate is likely to have been impacted as officers across the nation responded to these events. The survey remains open and it is hoped that response numbers will grow. This study represents a pulse survey, and more definitive conclusions will be possible as the numbers of responses to the survey increase over time. A final limitation involves the population from which the current sample was drawn. The survey was distributed exclusively to members of the FOP. While it is expected that the issues examined in this survey would not be impacted by membership in this group, future research should be conducted outside of this organization.

\section{CONCLUSION}

This research sought to provide a timely contribution to understanding the experiences of police serving during a global health pandemic. However, this story is not yet over, as the pandemic continues across the globe. It is unknown how long police will continue to serve under these conditions. This type of environment is impacting on police stress, impacting on their own, as well as their families', mental health and well-being. This research should act as a call to attention for police agencies to consider not only the physical toll that the pandemic will take on police but also psychological health. We should seek to build a comprehensive evidence base on which to design appropriate and effective interventions and strategies to keep our law enforcement communities and their families both physically and psychologically healthy.

\section{ACKNOWLEDGEMENTS}

The authors would like to acknowledge the support of the National Fraternal Order of Police for distribution of the survey to their members.

\section{CONFLICT OF INTEREST DISCLOSURES}

The authors have no conflicts of interest to declare. 


\section{AUTHOR AFFILIATIONS}

*Griffith Criminology Institute, Griffith University, Australia; ${ }^{\dagger}$ National Fraternal Order of Police, United States

\section{REFERENCES}

ABC. (2020, 31 March). Coronavirus News: NYPD has 5,600 officers out sick, 5 deaths. Retrieved 20 October 2020 from: https://abc7ny. com/nypd-coronavirus-deaths-nyc-news/6065991/

Blue H.E.L.P. (2020). Suicides to date by year. Retrieved 20 October 2020 https://bluehelp.org/

Bowler, R. M., Harris, M., Li, J., Gocheva, V., Stellman, S. D., Wilson, K., Alper, H., Schwarzer, R., \& Cone, J. E. (2012). Longitudinal mental health impact among police responders to the $9 / 11$ terrorist attack. American Journal of Industrial Medicine, 55, 297-312.

Carleton, R. N., Afifi, T. O., Taillieu, T., Turner, S., Mason, J. E., Ricciardelli, R., McCreary, D. R., Vaughan, A. D., Anderson, G. S., Krakauer, R. L., Donnelly, A. A., Camp, R. D. II, Groll, D., Cramm, H. A., MacPhee, R. S., \& Griffiths, C. T. (2020). Assessing the relative impact of diverse stressors among public safety personnel. International Journal of Environmental Research and Public Health, 17, 1234-1259.

Carlier, I. V., Lamberts, R. D., \& Gersons B. P. (1997). Risk factors for posttraumatic stress symptomatology in police officers: a prospective analysis. Journal of Nervous Mental Disorder, 185, 498-506.

Centers for Disease Control and Prevention (CDC). (2020). What law enforcement personnel need to know about Coronavirus disease 2019 (COVID-19). Retrieved 21 October 2020 from https:// www.cdc.gov/coronavirus/2019-ncov/downloads/guidance-lawenforcement.pdf

Chopko, B. A., Palmieri, P. A., \& Adams, R. E. (2015). Critical incident history questionnaire replication: Frequency and severity of trauma exposure among officers from small and midsize police agencies. Journal of Traumatic Stress, 28, 157-161.

Dazio, S., Sisak, M. R., \& Bleiberg, J. (2020). After COVID-19: Anxious, wary first responders back on job. Medicalxpress. Retrieved 20 October 2020 from https://medicalxpress.com/news/202004-covid-anxious-wary-job.html

Drew, J. M., \& Martin, S. (2020). Mental health and well-being of police in a health pandemic: Critical issues for police leaders in a post COVID-19 environment. Journal of Community Safety and Well-Being, 5(2), 31-36.

Frenkel, M. O., Giessing, L., Egger-Lampl, S., Hutter, V., Oudejans, R. R. D., Kleygrewe, L., Jaspaert, E., \& Plessner, H. (2021). The impact of the COVID-19 pandemic on European police officers: Stress, demands, and coping resources. Journal of Criminal Justice, 72, https://doi. org/10.1016/i.jcrimjus.2020.101756

Jennings, W. G., \& Perez, N. M. (2020). The immediate impact of COVID19 on law enforcement in the United States. American Journal of Criminal Justice, 6, 1-12.

Karaffa, K., Openshaw, L., Koch, J., Clark, H., Harr, C., \& Stewart, C. (2015). Perceived impact of police work on marital relationships. The Family Journal: Counseling and Therapy for Couples and Families, 23, 120-131.

Klimley, K. E., Van Hasselt, V. B., \& Stripling, A. M. (2018). Postraumatic stress disorder in police, firefighters, and emergency dispatchers. Aggression and Violent Behavior, 43, 33-44.

Laufs, J., \& Waseem, Z. (2020) Policing in pandemics: A systematic review and best practices for police response to COVID-19. International Journal of Disaster Risk Reduction, 51. https://doi.org/10.1016/i. ijdrr.2020.101812

Liu, B., Tarigan, L. H., Bromet, E. J., \& Kim, H. (2014). World Trade Center disaster exposure-related probable postraumatic stress disorder among responders and civilians: A meta-analysis. PLOS One, 9(7), e101491. https://doi.org/10.1371/journal.pone.0101491
Lowell, A., Suarez-Jimenez, B., Helpman, L., Zhu, X., Durosky, A., Hilburn, A., Schneier, F., Gross, R., \& Neria, Y. (2018). 9/11-related PTSD among highly exposed populations: A systematic review 15 years after the attack. Psychological Medicine, 48, 537-553.

Maguen, S., Metzler, T. J., McCaslin, S. E., Inslicht, S. S., Henn-Haase, C., Neylen, T. C., \& Marmar, C. R. (2009). Routine work environment stress and PTSD symptoms in police officers. Journal of Nervous Mental Disorder, 197(10), 574-760.

Margolin, J. (2020). White supremacists encouraging their members to spread coronavirus to cops, Jews, FBI says. ABC News. Retrieved 24 October 2020 from https://abcnews.go.com/US/whitesupremacists-encouraging-membersspread-coronavirus-cops-jews/ story? $\mathrm{id}=69737522$

Marshall, E. K. (2016). Cumulative career traumatic stress (CCTS): A pilot study of traumatic stress in law enforcement. Journal of Police and Criminal Psychology, 21, 62-71.

McQuerry Tuttle, B., Giano, Z., \& Merten, M. J. (2018). Stress spillover in policing and negative relationship functioning for law enforcement marriages. The Family Journal: Counselling and Therapy for Couples and Families, 26(2), 246-252.

National Fraternal Order of Police (FOP). (2020). COVID-19 line-of-duty deaths. Retrieved 24 October 2020 from https://fopcovid19.org/ news/covid-19-line-of-duty-deaths/

National Police Foundation (NPF). (2020). COVID-19 resources for law enforcement. Retrieved 22 October 2020 https://www.police foundation.org/covid-19/

Officer Down Memorial Page. (2020). Line of duty deaths. Retrieved October 20, 2020 from http://www.odmp.org

Papazoglou, K., Blumberg, D. M., Schlosser, M. D., \& Collins, P. I. (2020). Policing during COVID-19: Another day, another crisis. Journal of Community Safety and Well-Being, 5(2), 39-41.

Pole, N., Best, S., Weiss, D., Metzler, T., Liberman, A., Fagan, J., \& Marmar, C. (2001). Effects of gender and ethnicity on duty-related posttraumatic stress symptoms among urban police officers. Journal of Nervous and Mental Disease, 189(7), 442-448.

Prasad, R. (2020). Coronavirus: Why is there a US backlash to wear masks? BBC News. Retrieved 23 July 2021 from https://www.bbc. $\mathrm{com} /$ news/world-us-canada-52540015

Regehr, C., Carey, M. G., Wagner, S., Alden, L. E., Buys, N., Corneil, W., Fyfe, T., Matthews, L., Randall, C. White, C., Fraess-Phillips, A., Krutop, E., White, N., \& Fleischmann, M. (2019). A systematic review of mental health symptoms in police officers following extreme traumatic exposures. Police Practice and Research, 22(1), 225-239. https://doi.org/10.1080/15614263.2019.1689129

Rothstein, M. A. (2015). From SARS to Ebola: Legal and ethical considerations for modern quarantine. Indiana Health Law Review, 12, 227-280

Slocum, L. A. (2010). General strain theory and the development of stressors and substance use over time: An empirical examination. Journal of Criminal Justice, 38(6), 1100-1112.

Stogner, J., Miller, B. L., \& McLean, K. (2020). Police stress, mental health, and resiliency during the COVID-19 pandemic. American Journal of Criminal Justice. https://doi.org/10.1007/s12103-020-09548-y

Weiss, D. S., Brunet, A., Best, S. R., Metzler, T. J., Liberman, A., Pole, N., Fagan, J. A., \& Marmar, C. R. (2010). Frequency and severity approaches to indexing exposure to trauma: The Critical Incident History Questionnaire for police officers. Journal of Traumatic Stress, 23, 734-743.

West, C., Bernard, B., Mueller, C., Kitt, M., Driscoll, R., \& Sangwoo, T. (2008). Mental health outcomes in police personnel after Hurricane Katrina. Journal of Occupational and Environmental Medicine, $50(6), 689-695$ 